\title{
MATEMÁtica E Filosofia: Dos GRegos AtÉ DesCARTES
}

\author{
Irineu Bicudo $\dagger$ \\ Universidade Estadual Paulista - UNESP - Brasil \\ Duelci Aparecido de Freitas Vaz ${ }^{1}$ \\ Universidade Católica de Goiás - PUC Goiás/Instituto Federal de Goiás-IFG - Brasil
}

(aceito para publicação em setembro de 2018)

\begin{abstract}
Resumo
Este artigo trata da relação entre Matemática e Filosofia, dos gỏregos até Descartes. A pesquisa de cunho bibliográfico procurou estabelecer inicialmente a gênese da Matemática, mostrando que sua essência e origem estão na filosofia de Platão, possivelmente herdada do pitagorismo. Posteriormente, estabelece relações entre a Filosofia Aristotélica e a Matemática Euclidiana, mostrando essa proximidade nos Analíticos Posteriores, principalmente com relação aos axiomas, postulados e definições. No contexto histórico posterior à cultura grega, principalmente a efervescência cultural que se deu no final do século XVI e princípio do século XVII, as questões suscitadas no mundo científico, religioso, cultural e social culminaram na criação de novas Filosofias e de nova Matemática. Nesse período de transição, no qual os pensadores procuravam superar as ideias provenientes dos gregos, principalmente de Aristóteles (384-322 a. C.), Descartes vislumbrou uma nova forma de pensar a Matemática e a Filosofia, unindo-as. Para tanto, procurou um novo método; na verdade, retomou um método antigo, a saber, o método de análise e síntese dos antigos geômetras gregos. Desse modo, reconstituindo-o e reinterpretando-o, elaborou a sua metodologia. Assim, o método lhe permitiu estabelecer uma nova Filosofia inspirada na Matemática que pode ser resumida nas quatro regras anunciadas na parte inicial de sua obra O Discurso do Método. Por fim, o artigo mostra aplicações do método
\end{abstract}

\footnotetext{
${ }^{1}$ Quando produzimos este artigo, no início do ano de 2018, o professor Irineu Bicudo, ainda gozava de certa saúde. Quando recebi o comunicado que seria aceito para ser publicado na Revista Brasileira de História da Matemática, ele já tinha falecido. Aproveito este momento para homenageá-lo. Agradeço ao professor Irineu Bicudo pela dedicação e interesse no meu trabalho. Me conduziu a novos níveis cognitivos, me proporcionou nova vida acadêmica e profissional, principalmente na pesquisa. Os encontros semanais ficarão guardados em minha memória, momentos que nosso grupo de estudo discutia temas importantes, principalmente, ao desenvolvimento de minha tese. Nesses encontros, o professor Irineu Bicudo falava-nos de História da Matemática, de Matemática e de Filosofia, entre tantos outros temas. Com seu vasto conhecimento de línguas deu sugestões valiosas e influenciou minha escrita. Um erudito, cuja sensibilidade, inteligência e emoção pude constatar em diversos momentos. Agradeço sua contribuição à pesquisa na área de Educação Matemática e História da Matemática, sua escrita refinada em vários artigos e sua tradução de Os Elementos de Euclides nos conduziram a momentos especiais da História da Matemática. Ao amante dos livros, sua marca principal, minha sincera gratidão.
} 
cartesiano à Matemática e, neste caso, o método pode ser resumido em nomear, equacionar e construir. Articulado com a sua nova simbologia, o método o permitiu avançar em muitas questões da Matemática.

Palavras-chave: Matemática Euclidiana; Filosofia Moderna; Platão; Aristóteles.

\title{
[MATHEMatics ANd PhILOSOPHY: From the GreEKS to DeSCARTES]
}

\begin{abstract}
This article deals with the relation between Mathematics and Philosophy, from the Greeks to Descartes. The bibliographical research sought initially to establish the genesis of Mathematics, showing that its essence and origin are in the philosophy of Plato, possibly inherited from Pythagoreanism. Later, it establishes relations between the Aristotelian Philosophy and the Euclidean Mathematics, showing this proximity in the Later Analytics, mainly in relation to the axioms, postulates and definitions. In the historical context after Greek culture, especially the cultural effervescence that occurred in the late sixteenth and early seventeenth centuries, the issues raised in the scientific, religious, cultural and social world culminated in the creation of new Philosophies and new Mathematics. In this period of transition, in which the thinkers tried to surpass the ideas coming from the Greeks, mainly of Aristotle (384-322 a.), Descartes glimpsed a new way to think Mathematics and Philosophy, uniting them. To do so, he sought a new method; in fact, it took up an old method, namely the method of analysis and synthesis of ancient Greek geometers. In this way, reconstituting and reinterpreting it, he elaborated his methodology. Thus, the method allowed him to establish a new Philosophy inspired in Mathematics that can be summarized in the four rules announced in the initial part of his work The Discourse of the Method. Finally, the article shows applications of the Cartesian method to Mathematics and, in this case, the method can be summarized in naming, equating and constructing. Articulated with his new symbology, the method allowed him to advance in many questions of Mathematics.
\end{abstract}

Keywords: Euclidean Mathematics; Modern Philosophy; Plato; Aristotle.

\section{A origem da matemática grega e sua relação com a filosofia platônica}

É um fato comumente aceito por todos que a Matemática nasce na Grécia, onde ocorreu a transformação de uma Matemática empírica, herdada dos egípcios e dos babilônicos, em uma Matemática dedutiva, formal, tal como encontrada em $O s$ Elementos (III a. C) de Euclides. Essa transformação, certamente um grande momento da história da Matemática, ocorre, segundo a opinião de muitos historiadores, por meio da intervenção de Platão (428/7-2348/7 a. C.). Bicudo (1998) investiga essa transformação e chega à tese de que a mudança da Matemática "empírica" para a Matemática abstrata está intimamente associada ao caráter idealista, antiempírico da Filosofia eleática e, sobretudo, da Filosofia de Platão: 
"Verdade, que significa as ideias. São as ideias que têm Ser verdadeiro, não as coisas que são observadas pelos sentidos. As idéias podem, às vezes, ser contempladas, em momentos de Graça, através da reminiscência do tempo em que a alma vivia mais perto de Deus, no reino da Verdade; mas isso pode acontecer somente depois de os erros dos sentidos terem sido conquistados pelo pensamento concentrado. O caminho que leva a esse estado é aquele da dialética...".

Platão incentiva a estruturação dedutiva sistemática da Ciência Matemática, porque a considera propedêutica à dialética, pois "separando-se, ao mesmo tempo, dos pitagóricos, que mantinham no mesmo plano Ciência e Filosofia, e de Sócrates, cuja investigação prudente parece ter-se detido na determinação da hipótese, Platão conduz a Filosofia Matemática a um caminho todo novo. A

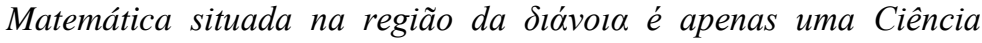

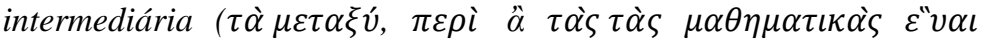

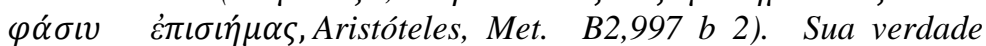
reside em uma Ciência superior, que está em relação a ela como ela mesma em relação à percepção do concreto. A dialética tem por função retomar as hipóteses das técnicas

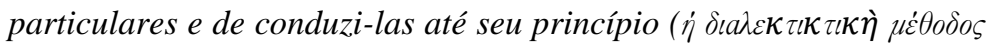

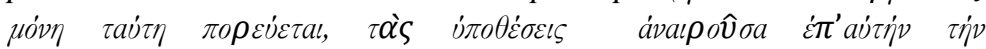
á $\chi \eta^{\prime} v$, REP.VII, 533c), ela toma posse do incondicional; e de lá, por uma marcha que é inversa à da análise, forja uma cadeia ininterrupta de ideias (REP. VI, 511b) que suspensa no princípio absoluto, constituirá um mundo completamente independente do sensível, o mundo da vónoıs. A Filosofia Matemática de Platão, em seu grau mais alto e sob sua forma definitiva será, então, a dialética (...)”. (BICUDO, 1998, p. 312-13)

A conclusão de Bicudo relata a gênese da Matemática grega e demonstra a sua íntima relação com a Filosofia de Platão. Com os gregos, a partir de então, a Filosofia e a Matemática mergulham num período áureo, pelo menos até o século IV (d. C.). Isso ocorreu para a Filosofia com o advento de Aristóteles e para a Matemática, principalmente com Euclides, que fundamenta a Geometria tendo por base três princípios, a saber: definições, postulados, noções comuns ou axiomas, a partir dos quais ele constrói a Geometria, a partir dos processos dedutivos.

Aristóteles, nos seus Analíticos, trata da teoria da Ciência. Lee em seu artigo Geometrical method and Aristotles's account of first principles (Método geométrico e a descrição de Aristóteles dos primeiros princípios) mostra a predominância da influência das ideias geométricas na descrição de Aristóteles dos primeiros princípios, nos Analíticos Posteriores - para mostrar que sua análise dos primeiros princípios é, em sua essência, uma análise dos primeiros princípios da Geometria, como ele os concebeu. A conclusão de Lee é como segue:

"Noções comuns de Euclides e Axiomas de Aristóteles, e as definições de ambos, são exatamente paralelas. As noções comuns e axiomas 
são princípios de argumentação cujo alcance estende mais do que aqueles de uma simples Ciência: as definições são afirmações do significado dos termos. Às hipóteses de Aristóteles respondem os postulados de Euclides. Ambos são um mínimo de suposições adicionais necessárias ao lado dos axiomas ou noções comuns e das definições. As hipóteses assumem existência, os postulados, a possibilidade de construção (...)”. (LEE, 1935, p. 117, tradução nossa).

A Matemática e a Filosofia gregas seguiriam interligadas e hegemônicas ainda por um longo período da história. Na Idade Média, estabeleceu-se a Escolástica, Filosofia da Igreja Católica, período marcado por uma forte censura às ideias científicas. Nenhuma nova Filosofia surgiu, pelo menos até o século XVI, assim como nenhuma Matemática além daquela dos antigos gregos. Porém, essa afirmação não significa que nada aconteceu nesse período. Houve uma discussão em torno dos trabalhos científicos dos gregos, que foi baseada nos ideais aristotélicos de que a Ciência se reestruturou na Escolástica. O aristotelismo escolástico não estava simplesmente preso às ideias antigas e não era só interpretativo da doutrina aristotélica. Ele também trouxe inovações importantes: era crítico, elevou as ciências matemáticas a um alto grau de importância e foi, até certo ponto, experimental.

Entretanto, esse estágio começou a ruir com o Renascimento e depois com a Reforma e a Contra Reforma. Com esses movimentos, a doutrina aristotélica começou a ser questionada e, entre as questões, a mais profunda diz respeito à metodologia científica, indicando a necessidade de uma nova concepção científica. A mudança mais importante que ocorreu foi, então, no âmbito científico. Foi necessário romper com o critério de Ciência estabelecido por Aristóteles. Além disso, o século XVI foi marcado por profundas modificações no plano religioso, moral, cultural e social e do saber em geral; exemplo disso são os vários debates travados nesse período.

No plano educacional, ocorreu o memorável confronto acadêmico entre o português Antônio de Gouveia e o francês Pierre de la Ramée, também conhecido como Petrus Ramus (1515-1572), ambos professores de Filosofia da Universidade de Paris. O confronto ocorreu a partir da dissertação de mestrado de Pierre de la Ramée: Quaecumque ab Aristotele dicta essent, commentitia esse (Tudo que Aristóteles disse foi forjado), de 1536.

No âmbito científico, um debate que merece destaque, ocorreu quase que paralelamente ao supracitado e é relatado, minuciosamente, no livro de Paolo Mancosu (1996) intitulado Philosophy of Mathematics and Mathematical Practice in the Seventeenth Century (A Filosofia da Matemática e a prática Matemática no século XVII). Mancosu sustenta que a concepção aristotélica de Ciência fomentou questões que orientaram a prática da Matemática do século XVII, afetando, inclusive, a metodologia da Matemática. As questões suscitadas dizem respeito à certeza da Matemática e ao enquadramento dela no esquema aristotélico de Ciência. Especificamente, os trabalhos de Euclides, Papus (III d. C.), Arquimedes (287-212 a.C.) e Apolônio (c. 262-c. 200 a. C.) foram colocados à prova.

A Quaestio debate, especificamente, a validade das demonstrações por superposição e demonstrações por contradição. As demonstrações por superposição tornaram-se centrais para os fundamentos dos indivisíveis e as demonstrações por contradição estimularam alguns matemáticos na tentativa de eliminá-las do 
desenvolvimento da Geometria. Esses conflitos conduziram a novas metodologias que permitiram avanços significativos em diversas áreas da Matemática no século XVII, a exemplo do Cálculo.

A influência da Filosofia e da Matemática gregas se faz presente nesse período de transição. Ao discutir a Filosofia grega e a certeza da Matemática grega são suscitadas várias questões importantes no âmbito científico. Esse é um momento marcante, pois o conhecimento matemático se desenvolveu rapidamente nos séculos XVI e XVII e as mudanças no campo da Matemática foram muito significativas. A Álgebra, a Geometria Projetiva, a Teoria da Probabilidade, o Cálculo e outras importantes áreas da Matemática foram profundamente afetadas pela algebrização e pela invasão das técnicas infinitistas que mudaram a direção da Matemática e, consequentemente, das Ciências em geral.

No âmbito religioso, foi marcante, nesse período, a Contra Reforma, reação da Igreja Católica à Reforma Protestante. Com o desenvolvimento comercial e urbano europeu, houve a necessidade de mudar certas regras estabelecidas pela Igreja, uma vez que se tornaram obstáculos no plano econômico; além disso, a Igreja havia incorporado certas concepções que passaram a ser vistas como contraditórias com os próprios ideais da doutrina cristã. Desse modo, ela passou a ser questionada e, em 1517, Martin Lutero (1483-1546), revoltado com a venda de indulgência, fixou na porta da catedral de Wittenburg um panfleto contendo 95 teses, denunciando abusos da Igreja e proclamando sua discordância em relação à orientação do papado. As bases do luteranismo foram expostas em 1530 na confissão de Angsburg, escritas por um discípulo de Lutero chamado Melanchthon (1497-1560).

De 1545 a 1563, a Igreja Católica organizou o Concílio de Trento, com representantes de toda a Europa, e preparou a Contra Reforma, reafirmando os seguintes pontos: confirmação da autoridade papal e da doutrina tradicional, confirmação da disciplina dentro da Igreja, fixação da idade mínima para funções eclesiásticas, instituição dos seminários, um catecismo para os fiéis com um resumo da doutrina cristã, um missal com orações e leituras básicas. Ficou também determinado que a Contra Reforma agisse para recuperar o espaço perdido para os protestantes com a criação de vários colégios destinados ao curso primário e a formação das novas gerações; criação da Companhia de Jesus, com a função de catequizar, recuperar e expandir o domínio da Igreja por todo o mundo, agora levando os seus ideais para além-mar e, por fim, a instituição da Inquisição. A reação foi marcada pela fundação da Companhia de Jesus, por Ignácio de Loyola (1491-1556), que fundou diversos colégios jesuítas por toda a Europa e também em outros continentes. Com eles, a Contra Reforma agiria desde muito cedo na formação do indivíduo e, com isso, no plano ideológico, preconizava os fundamentos da Igreja Católica.

O sucesso das escolas jesuítas foi nítido. Em 1579, a Companhia de Jesus contava com 180 colégios na Europa e 19 no resto do mundo. Em 1608, passa para 266. Em 1679, eram 455 e em 1710 somam 517 e ainda mantinha 95 colégios espalhados no Japão, Índia, África, e América Latina. Sem contar com outros gêneros de casas jesuítas. Na Europa, os jesuítas tinham colégios em Portugal, Rússia, Itália, Bélgica, França, Alemanha, Mônaco, Espanha, Áustria, Boemia, Polônia e Lituânia.

Durante mais de 200 anos, a Companhia de Jesus dominou o cenário educacional na Europa, estabelecendo escolas por toda parte, ininterruptamente até 21 de julho de 1773, quando foi decretado o fim da Companhia de Jesus, pelo Papa Clemente XIV. Somente a Rússia e a Prússia recusaram esse decreto, tornando-se os 
principais pontos de exílio dos jesuítas. A Ordem foi restaurada em sete de agosto de 1814, pelo Papa Pio VII, fundamentado nos benefícios da ação educacional dos jesuítas.

A Companhia de Jesus serviu duplamente aos interesses da Igreja Católica; como instrumento de Contra Reforma e para disseminar a ideologia católica por todo o mundo e afetou profundamente o cenário educacional europeu, produzindo um método pedagógico de ensino e unificando a forma de atuação dentro da Ordem, a Ratio Studiorum. A motivação era criar uma unidade acadêmica entre as centenas de escolas jesuítas, a parte curricular traz inovações importantes. Para entender o fenômeno da educação jesuíta, deve-se estudar a Ratio Studiorum, documento fundamental sobre o qual a proposta pedagógica dos jesuítas baseava-se. A elaboração desse documento se dá concomitantemente com o humanismo europeu. É um plano de estudo que pretendia abranger todas as escolas jesuítas, estabelecendo regras para todos os envolvidos nas escolas. O sistema escolar jesuítico passou, então, a ser bem estruturado: fica dotado de uma hierarquia que sujeitava todos a uma única autoridade que coordenava todas as ações, transferia professores para qualquer país e também recursos financeiros.

A versão definitiva da Ratio studiorum, que surgiu em 1599, foi fruto de quatro redações anteriores. As duas primeiras versões foram elaboradas em 1586 e são textos longos sobre os estudos superiores e inferiores. Já as duas últimas versões (de 1591 e 1599) são um conjunto de regras práticas para os reitores, prefeitos de ensino, professores e alunos; enfim, para toda a comunidade envolvida.

A gênese desse plano de estudo já se encontrava na parte IV das Constituições $^{2}$ da companhia de Jesus e dividia o ensino em três fases; Letras Humanas, Artes e Teologia. A primeira fase, de Letras Humanas ou Studias Humanitaris, era um pré-requisito às Ciências. O objetivo era dar ao aluno uma eloquentia perfecta, sem a qual ele não poderia ser capaz de ingressar nas Artes e na Teologia.

O currículo das escolas jesuítas eleva as Ciências Matemáticas, isto é, Aritmética, Astronomia, Geometria e Música, a um alto nível. A Companhia de Jesus é considerada por muitos uma academia de Ciências, devido ao grande número de cientistas que ela formou e que despontaram nas mais variadas áreas do saber, entre eles: Galileu (1564-1642), Descartes (1596-1650), Molière(1622-1673), Carlos Goldoni(1707-1793), Montaigne(1533 - 1592 ), Voltaire (1694 -1778), Anchieta(15341597), Antônio Vieira(1608-1697).

Outra característica desse período é a busca de uma linguagem universal para prover a Ciência emergente de uma nova ferramenta que explicasse os fenômenos do universo físico circundante. A Matemática apresenta-se, então, com a possibilidade de ser a base da Ciência. Exemplo disso é a Ciência de Galileu, fortemente embasada pelo ideal matemático. Existia, nesse período, a esperança de entender o mundo via Matemática, a língua da Ciência.

\footnotetext{
${ }^{2}$ Documento fundador da Companhia de Jesus, datado de 1539. Foi Inácio de Loyola quem redigiu as Constitutions. Esse documento era, como o nome indica, a Constituição dos jesuítas e orientava as ações dos jesuítas, resumindo métodos de atuação, propósitos, regras para ingresso e permanência na Ordem de Jesus. A quarta parte era destinada à educação e estava em vigor desde 1552; nela foram delimitadas as linhas mestras que a educação jesuíta deveria seguir e o espírito que deveria animar toda a ordem. O próprio Inácio exige que se devesse escrever um plano detalhado de ensino dentro da ordem. A Ratio nasce desse princípio.
} 
Descartes foi um desses que se aventuraram a encontrar o método que explicasse como tudo funcionava e por isso é considerado um filósofo importante, pois sua filosofia negou o legado de Aristóteles e, além de tudo, teve sucesso em muitas de suas empreitadas científicas ao utilizar seu método. Sua filosofia ficou reconhecida como um marco importante da modernidade. É difícil dizer com precisão o dia, a hora e o ano do nascimento da Filosofia Moderna, mas, com certeza, René Descartes é um de seus grandes expoentes. Ele frequentou a escola jesuíta de La Flèche, onde estudou durante oito anos. Mais tarde, com dezesseis anos, ingressou na Universidade de Pointers. Segundo consta, se interessou por vários ramos do saber: Medicina, Astronomia, Meteorologia, Matemática e Física.

Em 1637, ele publicou sua principal obra $O$ Discurso do Método, com três apêndices: A Geometria, A Dióptrica e Os Meteoros. Ali, diz ter estudado: Lógica, Geometria e Álgebra e que deveria olhar para métodos que combinassem as vantagens dessas três ciências, mas livres de seus defeitos. Assim, pode-se verificar a influência da Matemática sobre suas atividades intelectuais.

\section{A Matemática e a Filosofia moderna cartesiana}

Na parte II do Discurso do Método, Descartes propõe quatro regras, consideradas "o coração de sua filosofia", o núcleo de seu método:

"O primeiro consistia em nunca aceitar como verdadeira nenhuma coisa que eu não conhecesse evidentemente como tal; isto é, em evitar, com todo o cuidado, a precipitação e a prevenção, e nada incluir nos meus juízos que não se apresentasse de modo tão claro e distinto a meu espírito, que eu não tivesse ocasião alguma para dele duvidar.

$O$ segundo, em dividir cada uma das dificuldades que devesse examinar em tantas partes quanto possível e necessário para resolvêlas.

O terceiro, em conduzir por ordem meus pensamentos, iniciando pelos objetos mais fáceis de conhecer, para subir, aos poucos, gradativamente, ao conhecimento dos mais compostos, e supondo também, naturalmente, uma ordem de precedência de uns em relação aos outros.

E o quarto, em fazer, para cada caso, enumerações tão completas $e$ revisões tão gerais, que eu tivesse a certeza de não ter omitido nada”. (DESCARTES, 2002, com modificação, p. 31-2).

Entretanto, que relação existe entre o método cartesiano e a Matemática? Descartes diz, em seus escritos, que fora influenciado pelos matemáticos gregos Papus (III d. C.) e Diofanto (III d. C.) e que tais eruditos utilizavam um método de descoberta em Matemática. De fato, a obra de Papus, "A Coleção Matemática", contém exemplos de problemas resolvidos e teoremas demonstrados pelo método de análise e síntese dos antigos geômetras gregos e no livro ou capítulo VII, "O Tesouro da Análise", sua melhor descrição. Em “A Aritmética” de Diofanto encontramos uma álgebra sincopada 
e métodos algébricos criativos na resolução de diversos problemas algébricos (VAZ, 2007).

O método cartesiano é, de fato, adaptado do método de análise e síntese dos antigos gregos (VAZ, 2007). A parte analítica desse método consiste na busca da solução para a parte criativa do processo. É realizada, matematicamente, tomando o problema com todas as suas possibilidades, admitindo-o como resolvido e, a partir daí, busca-se decompô-lo, procurando asserções mais simples, dedutivamente, até chegar numa afirmação que se sabe ser verdadeira, finalizando, assim, a etapa analítica. A síntese começa a partir do fim da análise, retraçando seus passos, se for possível, encontra-se a solução do problema proposto.

Suponha, então, a título de ilustração, que se queira provar o simples resultado de que ângulos opostos pelos vértices são iguais, Fig. 1, usando o método acima mencionado. Então, se procede, num primeiro momento, aceitando o resultado desejado como já verdadeiro, ou seja, $A=C$. Em seguida, aplicando o axioma que diz que se iguais são adicionados a ambos os lados da igualdade, ela permanece verdadeira. Obtém-se a igualdade $A+D=C+D$, pelo acréscimo de $D$ a ambos os lados. Vale lembrar que a igualdade obtida nessa segunda etapa não precisa ser exatamente essa. Não há certeza na busca por antecedentes. Porém, deve-se agora perguntar, se essa última igualdade é verdadeira, o que se pode deduzir a partir dela? De acordo com a figura, $A+D$ deve ser igual a dois ângulos retos, $A+D=2 R$. O mesmo é válido para $C+D, C+D=2 R$. Portanto, chega-se a algo claramente verdadeiro. Isso indica o fim da análise. A síntese começa, neste caso, pela percepção de que, na figura, $A+D=2 R$ e $C+D=2 R$, ou seja, a síntese começa a partir da última etapa da análise. Aplicando agora o axioma que diz que coisas que são iguais à mesma coisa são iguais entre si, obtemos a seguinte igualdade, $A+D=C+D$. Aplicando o axioma que diz que se subtrairmos iguais de iguais os que permanecem são ainda iguais, obtém-se o resultado final, $A=C$. Isso conclui a etapa sintética. Como se vê, nesse exemplo, a etapa analítica pode ser considerada como sendo a descoberta dos possíveis caminhos que o matemático deve seguir para demonstrar o resultado. A etapa sintética é a demonstração do fato. Vale lembrar que teoremas complexos foram demonstrados por essa via, como está na obra de Papus.

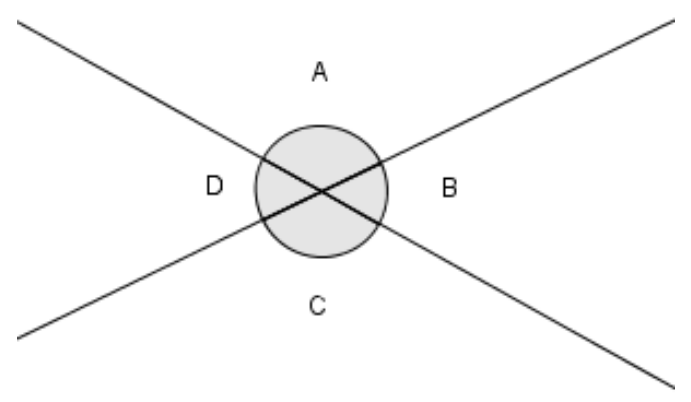

Figura 1 - Ângulos opostos pelo vértice. 
Descartes, inspirado por esse método geométrico, tentou fazer a transferência metodológica dos antigos geômetras gregos para outras áreas do conhecimento, inclusive, aplicando-o na própria geometria. Isso indica que o ideal metodológico grego foi retomado, mas com um grande diferencial, está voltado para questões mais amplas.

Interessa aqui ver a relação do método com a Matemática e vale dizer que Descartes afirma que é na Matemática que melhor aplica seu método. Por isso, analisase A Geometria, um dos apêndices de O Discurso do Método. Para compreender isso, faz-se uma análise de seu conteúdo e os problemas que foram ali tratados, com olhar especial para a aplicação do Método utilizado para resolvê-los.

A Geometria de Descartes é um marco na História da Matemática, pois está na origem da Geometria Analítica. Seu conteúdo pode ser dividido em três livros ou capítulos. O livro primeiro trata dos problemas que podem ser construídos sem usar mais do que círculos e retas. O livro segundo trata da natureza das curvas. O livro terceiro descreve a construção dos problemas sólidos ou mais que sólidos.

Não há muito em comum entre a Geometria cartesiana e a Geometria Analítica dos dias atuais. Não há, por exemplo, a ideia de vetor; além disso, os sistemas de coordenadas de Descartes não se parecem com os encontrados nos livros didáticos atuais.

\section{Livro I}

No livro I, Descartes indicou como as operações aritméticas se relacionam com operações geométricas. Ele ilustrou como realizar a multiplicação, a divisão e a extração da raiz quadrada geometricamente, isto é, com o uso de régua e compasso apenas; como empregar-se letras em Geometria; como resolver problemas geométricos ou o método de Descartes em Geometria; quais são os problemas planos e como resolvê-los. Descartes resolveu o problema de Papus para quatro retas aplicando o seu método pela primeira vez.

\section{Operações aritméticas}

Para os geômetras, dos gregos até Viète (1540-1603), a variável representava um comprimento; o produto de duas variáveis representava a área, o produto de três variáveis o volume. Já o produto de quatro ou mais variáveis não tinha significado específico. Essa interpretação grega passou a ser conhecida como obstáculo da dimensionalidade. Em sua geometria, Descartes introduziu o segmento unitário tornando possível e dando significado a muitos problemas que eram obstáculos para os gregos e, assim, rompeu com essa tradição de interpretar produtos entre variáveis, interpretando-os como grandezas unidimensionais (VAZ, 2005).

$\mathrm{O}$ autor introduziu uma nova simbologia que permite um avanço no campo da notação. Escrevia $a a$ ou $a^{2}$, aaa ou $a^{3}$, e assim sucessivamente. Na sua terminologia, o símbolo a podia ser interpretado como o comprimento de um segmento, e assim era com as outras potências $a^{4}$, $a^{5}$, etc. Usava o símbolo $\propto$ no lugar do atual igual (=). Escrevia $a+b$ para a soma de dois segmentos de comprimento $a$ e $b, a-b$ para a diferença, $a b$ para o produto, $a / b$ para o quociente, $\sqrt{a^{2}+b^{2}}$ para a raiz quadrada de $a+b$ e $\sqrt{C \cdot a^{3}+b^{3}+a b}$ para a raiz cúbica de $a^{3}-b^{3}+a b$, onde o $C$ significa cúbica. Justificava que $a$ tem tantas dimensões quanto $a b b$ e para se extrair a raiz cúbica de 
$a a b b-b$ deve-se considerar que a expressão $a a b b$ está dividida uma vez pela unidade e $b$ multiplicada duas vezes pela unidade. Descartes construiu todas as operações elementares usando régua e compasso. Para fazer o produto de a por $\mathrm{b}$, toma-se duas semirretas com mesma origem $\mathrm{B}$ e marca-se em uma delas o segmento unitário $A B$, veja Fig. (2). Em seguida, marca-se nessa mesma semirreta um segmento $B D$ de medida a e na outra semirreta o segmento $B C$ de medida b. Traça-se um segmento de $A$ até $C$ e, em seguida, partindo de $D$, traça-se outro segmento paralelo a $A C$ que encontra a outra semirreta em $E$ determinando o segmento $D E$. Usando semelhança ou o teorema de Tales, conclui-se que $B E$ vale $a b$.

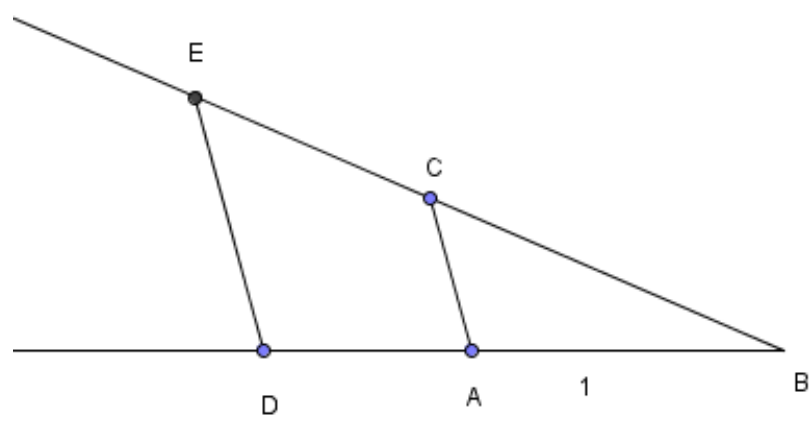

Figura 2 - A multiplicação de números geometricamente.

A divisão é realizada da seguinte maneira: tomam-se duas semirretas, como anteriormente, e marca-se o segmento unitário $A B$. Na outra semirreta marcam-se os segmentos $B C$ e $B E$, medindo respectivamente $a$ e $b, a<b$. Ligando $C$ a $A$ por um segmento e depois traçando um segmento paralelo a este segmento partindo de $E$ até $D$ determina-se $b / a$.

Para extrair a raiz quadrada, constrói-se um segmento unitário $F G$ acrescentando na sua extremidade o segmento de medida $K, G H$. Determina-se a semicircunferência cujo centro é o ponto médio do segmento determinado pela unidade e por $K$, veja Fig. (3). Em seguida constrói-se o triângulo retângulo levantando uma altura a partir do ponto $G$ até $I$, ponto que está sobre a circunferência do círculo construído, e usando a relação $G I^{2}=G H \times F G=G H$, obtém-se a raiz quadrada. 


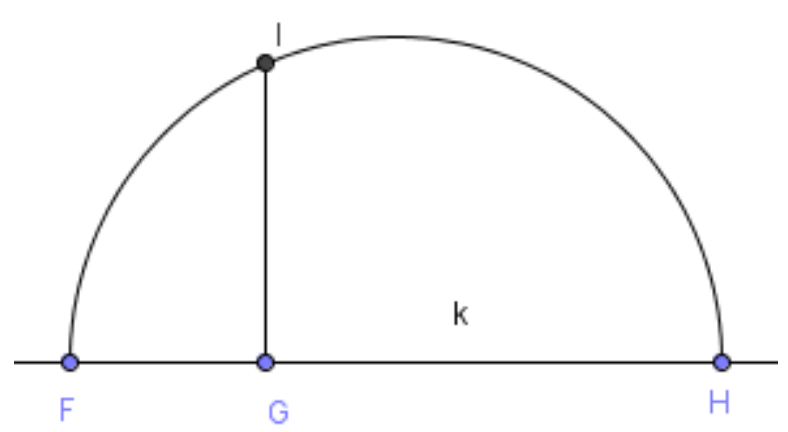

Figura 3 - Raiz quadrada geometricamente.

\section{Problemas planos}

Para Descartes, problemas planos são aqueles que podem ser resolvidos utilizando-se apenas linhas retas e segmentos circulares, traçados sobre uma superfície plana. Esses são os problemas que se reduzem a uma expressão da forma $z-a z= \pm b$. Descartes não considerava as raízes negativas dessas equações, as quais chamava de falsas. A construção dessas raízes é realizada como segue. Considere a equação $z^{2}=a z$ $+b$, sendo $z$ o termo ou segmento desconhecido. Primeiro, constrói-se o triângulo retângulo $N L M$, com $L M=b$ e $L N=a / 2$, depois o círculo de centro $N$ e raio $N L$ - veja Fig. (4). Prolongando a base do triângulo $L M N$ até $O$, de modo que $N O$ seja igual a $N L$, então a linha $M O$ é o segmento $z$. Aqui vale observar, seguindo a tradição grega, que Descartes chama de base a hipotenusa do triângulo retângulo, pois os gregos construíam o triângulo retângulo apoiado sobre a hipotenusa. A palavra hipotenusa, então, indica aquele lado que está sob o ângulo reto.

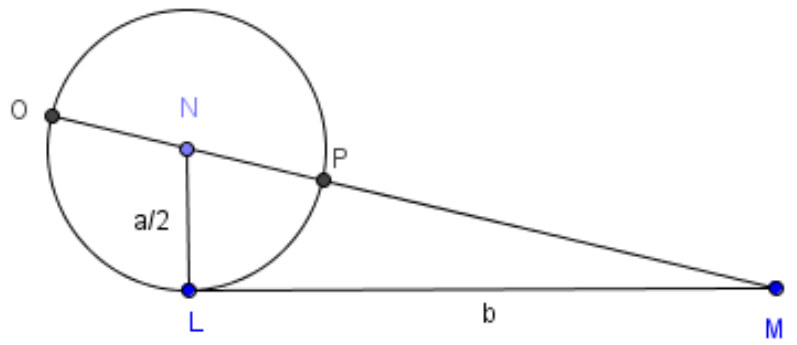

Figura 4 - Resolução da equação $z^{2}=a z+b$ geometricamente.

Equação $z^{2}=a z-b$. Seja $N L=a / 2, L M=b$. Descartes constrói o círculo de centro $N$ e raio $N L$, veja Fig. (5). Constrói em seguida $L M$ perpendicular a $N L$. Traça a partir de $M$ uma paralela a $N L$ que corta o círculo em $Q$ e $R$. O segmento $z$ será $M Q$ ou $Q R$. Se a paralela não corta o círculo o problema não tem solução. 


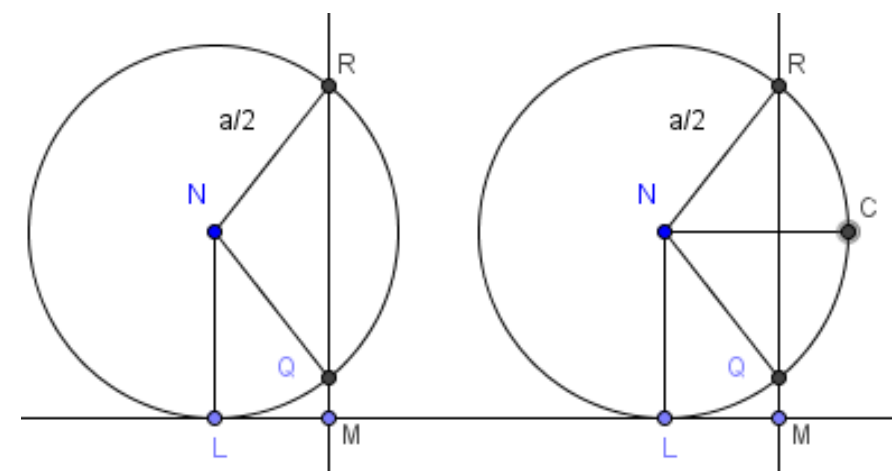

Figura 5 - Resolução da equação $z^{2}=a z-b$ geometricamente.

\section{O Método de Descartes e o problema de Papus}

Inicialmente, Descartes aplica seu método de maneira significativa para resolver o problema de Papus, um problema já conhecido pelos gregos anteriores a Papus. O Problema pode ser enunciado, considerando quatro retas: $A B, A D, E F e G H$. Encontrar um ponto $C$ tal que, dados ângulos $\alpha, \beta, \gamma e \varphi$ fixos, obtidos traçando retas por $C$ até $A B, A D, E F, G H$, respectivamente, tal que $C B . C F=C D . C H$, veja Fig. 6. Mais ainda, traçar e conhecer a curva contendo tais pontos. Descartes inovou no tratamento desse problema, reduzindo-o a duas variáveis, o que permite, atribuindo-se valores a uma delas, determinar os valores correspondentes da outra variável e, a partir daí, conhecer o lugar geométrico dos pontos.

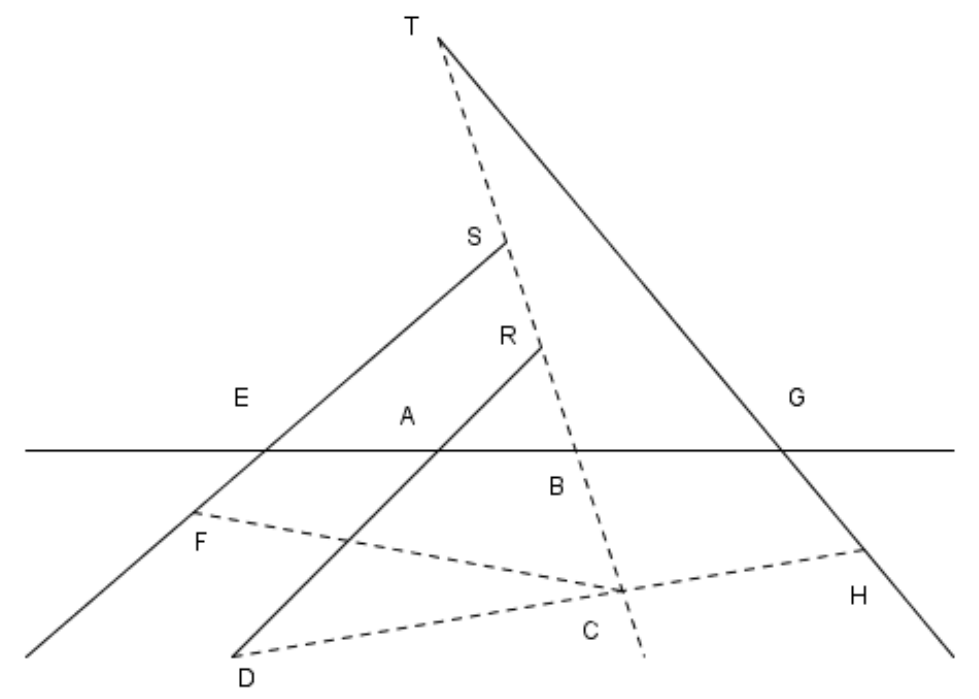

Figura 6-O problema de Papus para quatro retas. 
Na passagem a seguir, nota-se a estratégia de Descartes:

Primeiro supondo o problema resolvido e, para sair da confusão de todas estas linhas, considero uma das dadas e uma das que há que encontrar, por exemplo, $A B$ e $C B$, como as principais, às quais trato de referir todas as outras. Designe por $x$ o segmento de linha $A B$ compreendido entre os pontos $A$ e $B$; e seja $C B$ designado por $y$; e prolonguem-se todas as demais linhas até que cortem também estas duas, prolonga- das se necessário e se não lhe são paralelas; como se vê elas cortam a linha $A B$ nos pontos $A, E, G$ e a linha $B C$ nos pontos $R, S, T$. Ora bem, como todos os ângulos do triângulo $A R B$ são dados, a proporção dos lados $A B$ e $R B$ é também dada, e indico-a como de $z$ para $b$; de maneira que representando $A B$ por $x, R B$ será $b x / z$ e a linha total $C R$ será $y+b x / z$, pois o ponto $B$ cai entre $C$ e $R$; se $R$ caísse entre $C$ e $B$ seria $C R=y-b x / z$ e se caísse entre $B$ e $R$, seria $C R=-y+b x / z$. Analogamente, os três ângulos do triângulo $D R C$ são dados e, por conseguinte, também a proporção que há entre os lados $C R$ e $C D F$, indico como $z$ para $c$, de modo que sendo $C R=y+b x / z$, será $C D=c y / z+b c x / z^{2}$. Após isto, como as linhas $A B, A D$, e $E F$ são dadas em posição, a distância entre os pontos $A$ e $E$ também é dada e, designando-as por $k$, ter-se-á $E B$ igual a $x+k$; que seria $k-x$ se o ponto $B$ caísse entre $E A ; e-k+x$ se $E$ caísse entre $A$ e $B$. E como todos os ângulos do triângulo $E S B$ são dados, e estabelecendo que $B E$ está para $B S$ assim como $z$ está para $d$, tem-se: $B S=(d k+d x) / z$ e a linha $C S$ é $(z y+d k+d x) / z$. Se o ponto $S$ caísse entre $B$ e $C$ seria $C S=(z y-d k--$ $d x$ ) e quando $C$ cai entre $B$ e $S$ teremos $C S=(-z y+d k+d x) / z$. Além disso, os três ângulos do triângulo $F S C$ também são conhecidos, e, portanto é dada a proporção de $C S$ para $C F$, que z para e, e será $C F=(e z y+d e k+d e x) / z^{2}$. Analogamente, $A G$ ou $l$ é dada e $B G$ é $l-x$, pois no triângulo $B G T$ é também conhecida a proporção $B G: B T=z / t$, teremos: $\quad B T=(f l-f x) / z$, sendo $C T=(z y+f l-f x) / z$. Agora, como a proporção de $T C$ para $C H$ está dada pelo triângulo $T C H$, fazendo-a como $z$ para $g$, tem-se $C H=(g z y+f g l-f g x) / z^{2}$. (DESCARTES, 2001, p. 21, 22)

Substituindo em $C B . C F=C D$. $C H$ obtém-se uma equação do segundo grau em $x$ e $y$. Atribuindo um valor a uma das variáveis, encontra-se a segunda. Como isso pode ser feito indefinidamente, determina-se uma infinidade de pontos e a partir deles é possível construir a curva que representa o lugar geométrico. A construção dessa equação foi dada anteriormente, pois, ao atribuir um valor a uma das variáveis, obtémse uma equação do segundo grau.

A resolução do problema de Papus, dada por Descartes, é reconhecida como a base para o desenvolvimento da Geometria Analítica. Pelo exemplo, nota-se que Descartes apresentou o método que pode ser dividido resumidamente em três etapas: nomear, equacionar, construir. Nomear consiste em assumir que o problema já está resolvido e, a partir daí, nomear ou atribuir variáveis a todos os segmentos conhecidos e desconhecidos necessários para a resolução do problema. Equacionar significa estabelecer uma equação modelada a partir da situação dada, envolvendo essas 
variáveis. Finalmente, construir as soluções geometricamente, fazendo uso de régua e compasso. Acrescente-se aqui, conforme prevê o método, fazer uma análise profunda de todas as etapas para que não paire dúvida no processo.

Quanto ao método aplicado, é necessário esclarecer sua relação com o método de análise e síntese dos antigos geômetras gregos e aquele descrito na parte II do Discurso do Método. A etapa analítica começa quando Descartes o decompôs, nomeando todos os segmentos e estabelecendo equações que, no final, são reduzidas a uma simples equação capaz de sintetizar o problema. A etapa sintética é a construção da equação. Descartes dedicou boa parte de seu livro explicando como construir tais equações e no Livro II explorou todas as possibilidades do problema de Papus: a ideia é resolvê-lo completamente e generalizá-lo para mais de linhas.

\section{Livro II}

O segundo livro pode ser dividido em quatro partes. A primeira apresenta a classificação de curvas de Descartes, contendo uma análise completa das curvas necessárias para resolver o problema de Papus para quatro retas e para o caso especial de cinco retas. Ele apresenta o método da normal ou da tangente, onde se pode visualizar outra aplicação do método. Apresenta também aplicações à Dióptrica, especificamente problemas relacionados às ovais ou elipses, úteis na época para a construção de telescópios.

\section{Curvas geométricas e curvas mecânicas} entende que:

Segundo Descartes, as curvas podem ser geométricas ou mecânicas. Descartes

(...) por geométrico é o que preciso e exato, e por mecânico o que não o é, e considerando a geometria como uma ciência que ensina geralmente a conhecer as medidas de todos os corpos, não devem excluir-se as linhas por composta que sejam, enquanto possam imaginar-se descritas por um movimento contínuo, ou por vários que se sucedem, e em que os últimos estão inteiramente regidos pelos que os precedem; pois por este meio se pode sempre ter um conhecimento exato da sua medida. (DESCARTES, 2001, p. 29)

No decorrer do texto, ele admite como curvas geométricas aquelas geradas por um movimento contínuo e regulado, como aquele obtido por uma espécie de máquina onde as engrenagens estão interligadas, (Fig. 7), ao mover o eixo XY todos os pontos $\mathrm{B}, \mathrm{D}, \mathrm{F}, \ldots$, movem-se, formando as curvas geométricas. Algumas geradas por construções ponto a ponto e as dadas por uma equação algébrica também são consideradas geométricas. A quadratriz é uma curva que pode ser construída ponto a ponto, mas não foi considerada por Descartes. 


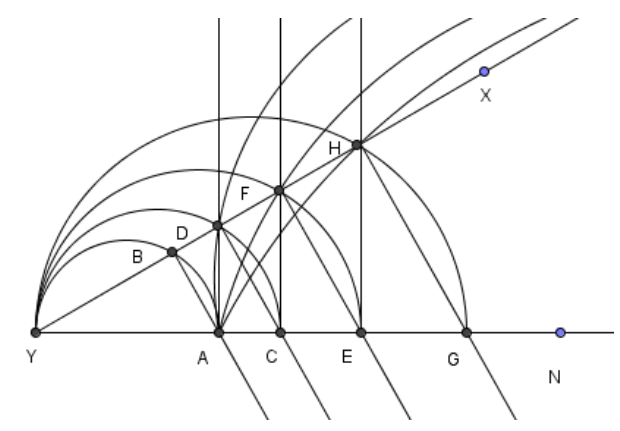

Figura 7 - Obtenção de curvas geométricas.

As curvas mecânicas não podem ser descritas por uma equação algébrica. Mais tarde, Leibniz as chamou de transcendentes (VAZ, 2007). Em curvas descritas por dois movimentos separados, somente pontos especiais podem ser construídos; curvas que algumas vezes são retas e algumas vezes são linhas curvas são também consideradas mecânicas. São exemplos de curvas mecânicas: a quadratriz, a espiral e a hélice. Mancosu (1996, p.78) afirma que um dos critérios usados para excluir as curvas mecânicas da Geometria, como é o caso da quadratriz, é o fato de ela ser usada para quadrar o círculo, impossível com régua e compasso e, portanto, não pode trazer nada de novo à Geometria. Para Gillies (1992, p.101) a grande visão de Descartes consistia em classificar todos os problemas geométricos por meio de curvas simples que podem ser usadas para resolvê-los.

Descartes apresentou uma análise completa das curvas necessárias para resolver o problema de Papus para quatro retas e para o caso especial de cinco retas. Ele explorou todas as possibilidades do problema de Papus quando está proposto para quatro e três retas, mostrando que não se obterá mais que as seções cônicas. O caso para três retas é realizado considerando a terceira e quarta retas coincidindo. Neste caso, a proporção fica $C B . C F=C D$. $C D$. O caso especial para cinco retas é quando se toma quatro delas paralelas e a quinta perpendicular a essas quatro. A estratégia básica é a mesma usada anteriormente. A generalização do problema de Papus consiste em notar, como fez Descartes, que a distância de C a cada reta é uma expressão de duas variáveis do tipo $a x^{2}+b y+c$. Ao substituir na condição dada, teremos um produto em cada membro, com n fatores para o caso de $2 n$ ou $2 n-1$ retas.

Passa-se, agora, à análise de outra aplicação do método, no cálculo da normal ou tangente. Para apresentá-lo, Descartes aplicou-o à elipse, veja Fig. 8, e, mais uma vez, usou seu método para resolver problemas em Geometria como se explica a seguir. Seja $C P$ a reta perpendicular à elipse $C E$ em $C$. $C E$ é a elipse, $M A$ um segmento contido em seu diâmetro (eixo) ao qual corresponde à ordenada $C M$. Seja a elipse com equação $x^{2}=r y-(r / q) y^{2}$. Usando o teorema de Pitágoras, obtém-se a equação $s^{2}=x^{2}+v$ $2 v y+y^{2}$. Substituindo uma na outra, chega-se à equação $y^{2}+\left(q r y-2 q v y+q v y+q v^{2}-\right.$ $\left.q s^{2}\right) /(q-r)=0$. Como $C P$ deve ser normal à elipse, então o círculo com raio $C P$ deve tocar a elipse em um único ponto $C$, logo a equação resultante tem raiz dupla e pode ser reescrita na forma $(y-e)=0$, onde $e$ é a raiz; desenvolvendo-a chega-se a $y=2 y e-e$, comparando temos, $e=(2 q v-q r) /(q-r)$, resolvendo-a em $v$, tem-se $v=(2 e(q-r)+q r) / 2 q$ e como $e=y$, tem-se, finalmente, a $v=y(q-r) / q+r / 2$. Por fim, resta construir a equação que 
é a parte mais fácil, pois requer construções básicas. Note que o método da normal de Descartes não utiliza a ideia de limite, que surgiria com Fermat (1601 - 1665).

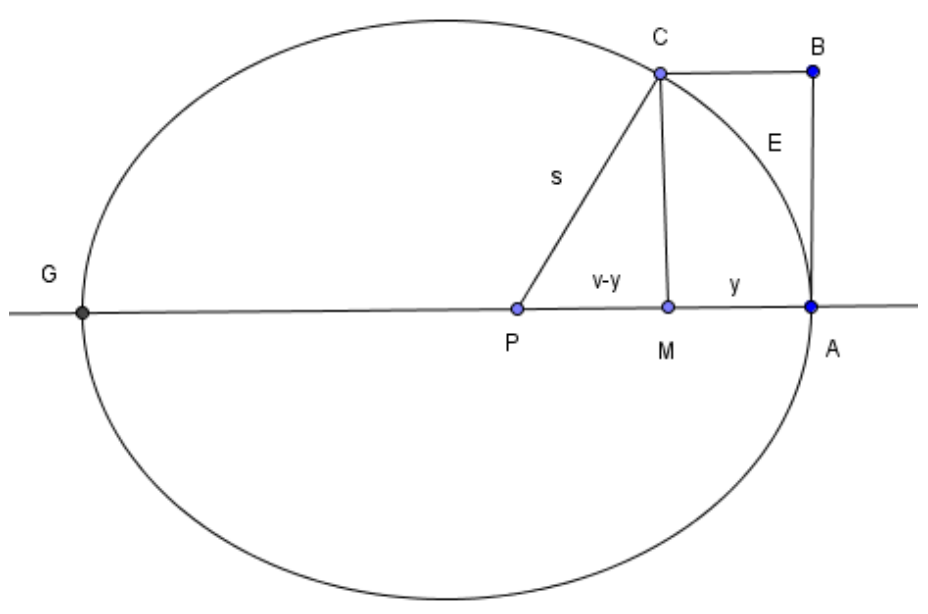

Figura 8 - O problema da normal.

Constata-se, nesse exemplo, a mesma estratégia usada para resolver o problema de Papus: nomear, equacionar e construir.

\section{Livro III}

O terceiro livro apresenta uma análise completa das raízes de equações polinomiais, a regra de sinal de Descartes, a construção de todos os problemas de terceiro e quarto grau, através da intersecção de um círculo e uma parábola, e a redução de todos esses problemas ao da trissecção de um ângulo ou da construção dos meios proporcionais. $\mathrm{O}$ livro três começa esclarecendo quais são as curvas geométricas que se deve escolher para resolver os problemas em Geometria. Assim, diz Descartes (2001, p. 99):

(...) não pode dizer que seja lícito servir-se da primeira que se encontra para a construção de cada problema, pois é necessário ter o cuidado de escolher sempre a mais simples que permita resolvê-lo. E é ainda necessário observar que deve entender-se por mais simples as que possam ser mais facilmente traçadas, nem as que tornam a construção ou a demonstração do problema mais fácil, mas principalmente as que, sendo da classe mais simples, possam servir para determinar a grandeza que se busca.

O autor apresenta, em seguida, o processo de determinar os meios proporcionais em uma construção, uma vez que isto é bastante importante em sua teoria 
para resolver problemas sólidos. Na sequência, ele traz as propriedades das equações polinomiais com coeficiente reais e suas raízes, chamando as raízes reais e positivas de verdadeiras e as negativas de falsas. A variável é chamada de quantidade desconhecida. O coeficiente da variável, quantidade conhecida. A ausência de um termo na equação é indicada por um sinal asterisco (*). O grau da equação é, para ele, a dimensão.

As propriedades apresentadas em A Geometria são, em muitos casos, parecidas com aquelas que encontramos nos livros de Matemática do terceiro ano do ensino médio. Destaca-se, entre essas propriedades, a regra de sinal de Descartes. A importância dada a essas propriedades é que elas são usadas, por ele, para resolver problemas em Geometria, que recaem em equações algébricas. A quantidade de raízes de uma equação, para Descartes, é igual à dimensão. Isto sugere que ele já conhecia o teorema fundamental da Álgebra, embora em A Geometria não apareça nenhum comentário sobre isso.

Cabe aqui ressaltar a Regra de Sinal: tomemos o exemplo dado em A Geometria quando ele fala das raízes da equação $x^{4}-4 x^{3}-19 x^{2}+106 x-120=0$ :

(...) podem existir tantas verdadeiras como de vezes os sinais $+\mathrm{e}-\mathrm{se}$ encontrem trocados; e tantas falsas como de vezes se encontrem dois sinais + ou dois sinais - seguidos. Assim, na última, depois de $+x$ segue - $4 x$, há uma variação de sinal de + para -; e depois de $-19 x$ segue-se $+10 x$ e depois de $+106 x$ vem -120 , o que corresponde a outros dois câmbios, donde se conclui que há três raízes verdadeiras; e uma falsa, em virtude dos dois sinais seguidos que antecedem $4 x \mathrm{e}$ 19x. (DESCARTES, 2004, p. 105-6)

Hoje a regra poderia ser enunciada assim: o número de raízes positivas de uma equação algébrica ou é igual ao número de variações de sinal na sequência dos coeficientes ou é menor que esse número por um inteiro par.

\section{Conclusão}

Este estudo permitiu concluir que, embora muitas realizações de Descartes estejam superadas, como é o caso da classificação de curvas, ele conseguiu dar contribuições importantes à Matemática e à Filosofia de sua época. Em A Geometria, percebe-se isso claramente: sua moderna notação e a indicação de como operar algebricamente com segmentos permitiu-lhe avançar significantemente em muitos resultados. Na resolução dos problemas apresentados, percebe-se a eficácia desta notação, pois lhe permite tratar de questões gerais, superando seus antecessores que possuíam uma notação algébrica complexa, o que lhes impossibilitava generalizar resultados e trabalhar com facilidade. Quanto à adaptação de seu método aplicado à |Geometria, herdado dos antigos matemáticos gregos, junto com sua simbologia, nota-se sua eficiência na resolução de diversos problemas, como o de Papus e o da determinação da normal. Percebe-se que a ideia de nomear os termos dados num problema, determinar uma equação envolvendo todos esses termos e obter a solução é, ainda hoje, uma estratégia muito útil no ensino da Matemática, embora para Descartes as raízes tivessem que ser construídas geometricamente. Quanto à criação da Geometria Analítica, pode-se afirmar que na obra cartesiana não existem as ideias usuais da geometria analítica como vetores, 
equações de retas e planos. Isso teria que esperar um pouco mais. Forbes (1977) afirma que, de fato, a criação da Geometria Analítica é fruto de um longo desenvolvimento histórico antes e depois de Descartes, o que corrobora nossa análise.

\title{
Referências
}

BICUDO, I. Platão e a Matemática. In: Revista Letras Clássicas, v. 2, 301-315. São Paulo. 1998.

DESCARTES, René. A Geometria. Tradução Emídio César de Queiroz Lopes. Lisboa: Editorial Prometeu, 2001.

DESCARTES, René. O Discurso do Método. Tradução de Pietro Nasseti. São Paulo: Martin Claret, 2002.

FORBES, Eric G. Descartes and the Birth of Analytic Geometry. Historia Mathematica. London 4. p. 141-151, 1977.

GILLIES, Donald. Revolutions in Mathematics. N. York: Nova York: Oxford University Press, 1992.

LEE, H. D. P. Geometrical Method and Aristotle's account of first principle. In: The Classical Quarterly. v. 29, n. 2, 113-124, 1935.

MANCOSU, Paolo. Philosophy of Mathematics and Mathematical Practice in the Seventeenth Century. N. York: New York: Oxford University Press, 1996.

VAZ, D. A. F. A Geometria de Descartes. In: Bolema - Boletim de Educação Matemática, n. 23, 113-122. Rio Claro: EDUNESP, 2005.

VAZ, D. A. F. A Influência da Matemática nas Regras para Direção do Espírito e $O$ Discurso do Método. Tese (Doutorado) — UNESP, Rio Claro, 2007.

VAZ, D. A. F. Estudos Cartesianos: a formação acadêmica. Goiânia: Ed. da PUC Goiás, 2007.

\author{
Irineu Bicudo ${ }^{\dagger}$ \\ Universidade Estadual Paulista - UNESP - Brasil. \\ Duelci Aparecido de Freitas Vaz \\ Universidade Católica de Goiás - PUC Goiás / \\ Instituto Federal de Goiás-IFG - Brasil. \\ E-mail: duelci.vaz@gmail.com
}

